\title{
MANUAL EDUCATIVO PARA O AUTOCUIDADO DA MULHER MASTECTOMIZADA: UM ESTUDO DE VALIDAÇÃO ${ }^{1}$ EDUCATIONAL HANDBOOK FOR SELF CARE IN WOMEN WITH MASTECTOMIES: A VALIDATION STUDY MANUAL EDUCATIVO PARA EL AUTOCUIDADO DE LA MUJER MASTECTOMÍZADA: UN ESTUDIO DEL VALIDACÍÓN
}

\author{
Mariza Silva de Oliveira², Ana Fátima Carvalho Fernandes³, Namiê Okino Sawada ${ }^{4}$
}

${ }^{1}$ Extraído da Dissertação de Mestrado “Autocuidado da mulher na reabilitação da mastectomia: estudo de validação de
aparência e conteúdo de uma tecnologia educativa”, defendida em 2006 no Departamento de Enfermagem da Universidade
Federal do Ceará (UFC).
${ }^{2}$ Mestre em Enfermagem Clínico-cirúrgica. Doutoranda em Enfermagem pelo Programa de Pós-Graduação em Enfermagem
da UFC. Bolsista da Coordenação de Aperfeiçoamento de Pessoal de Nível Superior. Ceará, Brasil.
${ }^{3}$ Doutora em Enfermagem. Professora Adjunto do Departamento de Enfermagem da UFC. Orientadora da dissertação.
Ceará, Brasil.
${ }^{4}$ Doutora em Enfermagem. Professora Associado do Departamento de Enfermagem Geral e Especializada da Escola de
Enfermagem de Ribeirão Preto da Universidade de São Paulo. São Paulo, Brasil.

PALAVRAS-CHAVE: Tecnologia educacional. Estudos de validação. Cuidados de enfermagem. Neoplasias mamárias.
RESUMO: Pesquisa de desenvolvimento metodológico que objetivou validar manual educativo para o autocuidado da mulher mastectomizada, utilizando a etapa teórica do modelo de Pasquali. Os dados foram coletados em maio-junho de 2006, em dois momentos: $1^{\circ}$ ) análise de conteúdo por 14 juízes e $2^{\circ}$ ) análise semântica por 9 mulheres mastectomizadas. Os questionários foram organizados na escala Likert com itens distribuídos em blocos e analisados através da estatística descritiva. A validação proposta foi satisfatória pela análise dos avaliadores, pois a maioria das respostas recebeu conceitos adequados, não apresentando discordância em ambas as avaliações. Quanto ao parâmetro de $80 \%$ de concordância nos conceitos, 14 itens atingiram a meta proposta, 4 tiveram índices limítrofes e 4 abaixo do parâmetro. Considera-se que o manual validado pode contribuir para a promoção da saúde, prevenção das complicações, desenvolvimento de habilidades de seus usuários e favorecer a autonomia e a motivação da enfermagem para inventar novas tecnologias extraídas da práxis.
KEYWORDS: Educational technology. Validation studies. Nursing care. Breast neoplasms.

\begin{abstract}
This is a methodological development study which aims to validate an educational handbook for self-care among women with mastectomies, using the theoretical stage of the Pasquali model. The data collection took place from May to June of 2006 in two methodological periods: 1st) content analysis by 14 judges; and 2nd) semantic analysis by 9 women with mastectomies. The questionnaires used were organized according to Likert with items distributed in block and analyzed through descriptive statistics. The validation proposal was satisfactory for the analysis of the evaluators, for the majority of the answers received adequate concepts, not presenting disagreement in either evaluation. As to the parameter of $80 \%$ agreement among the concepts, 14 items reached the proposed goal, 4 had limiting indexes and 4 were below the parameter. We consider that the validated handbook can contribute to health promotion, prevention of complications, development of abilities of their users, and favor nursing autonomy and motivation in order to create new technologies extracted from praxis.
\end{abstract}

PALABRAS CLAVES: Tecnología educacional. Estudios de validación. Atención de enfermería. Neoplasias de la mama.

\begin{abstract}
RESUMEN: Investigación de desarrollo metodológico que tuvo como objetivo validar un manual educativo para el autocuidado de la mujer mastectomizada. Para ello fue utilizada la etapa teórica del modelo de Pasquali. La recolección de los datos fue realizada en el período de mayo a junio de 2006, en dos momentos metodológicos, a saber: $1^{\mathrm{a}}$ ) el análisis de contenido por 14 jueces, $\mathrm{y}, 2^{\mathrm{a}}$ ) el análisis semántico por 9 mujeres mastectomizadas. Los cuestionarios usados fueron organizados en la escala Likert con apartados distribuidos en secciones y analizados por medio de la estadística descriptiva. Según el análisis de los evaluadores, la validación propuesta fue satisfactoria, ya que la mayoría de las respuestas recibieron conceptos adecuados, sin presentar discordancia en ninguna evaluación. En relación al parámetro de $80 \%$ de concordancia en los conceptos, 14 puntos alcanzaron la meta propuesta, 4 tuvieron índices limítrofes, y, 4 por debajo del parámetro. Se considera que el manual validado puede contribuir para la promoción de la salud, la prevención de las complicaciones, el desarrollo de habilidades de sus usuarios y favorecer la autonomía y la motivación de la enfermería para crear nuevas tecnologías extraídas de la praxis.
\end{abstract}

Mariza Silva de Oliveira

Endereço: R. Sete, Conj. Planalto Itaperi, casa 31

60.761-310 - Itaperi, Fortaleza, CE, Brasil.

E-mail: marizaenfa@yahoo.com.br
Artigo original: Pesquisa

Recebido em: 16 de julho de 2007 Aprovação final: 10 de janeiro de 2008 


\section{INTRODUÇÃO}

A prática da enfermagem tem sido fortemente influenciada pelos avanços tecnológicos que a sociedade vem sofrendo. Entretanto, mesmo com esse advento e as diversas descobertas na área da saúde, grande parte dos recursos tecnológicos existentes ainda não atingem toda a comunidade. Diante destas lacunas, faz-se necessária a utilização de tecnologias alternativas, pois acredita-se que essas possuam melhor acessibilidade e a mesma eficiência, após validação e testagem. ${ }^{1}$

A utilização de tecnologias criadas pelas próprias enfermeiras como instrumentos que auxiliam o seu trabalho é pouco divulgada, e as publicações em periódicos de enfermagem sobre essa temática ainda são escassas. A primeira exposição tecnológica de enfermagem foi apresentada no $44^{\circ}$ Congresso Brasileiro de Enfermagem, realizado em Brasília, em 1992. Desde então, a Associação Brasileira de Enfermagem tem propiciado este espaço para a divulgação de tecnologias e inventos de enfermeiros, materializando essa proposta por meio de mostras em outros congressos. ${ }^{2}$

Ao longo dos anos, podemos observar que a Enfermagem vem, ainda que de forma incipiente, produzindo, elementos construtivos de produção tecnológica, mesmo que essa produção não venha sendo, majoritariamente, composta por artefatos e inventos, mas que incluem estratégias para controlar o processo de trabalho ou a estruturação de material didático-pedagógico para diferentes clientes. ${ }^{3}$

No entanto, é do conhecimento da comunidade científica da enfermagem a existência de alguns inventos dos enfermeiros para auxiliar no cuidado aos pacientes e na implementação de suas rotinas, assim como a criação de tecnologias para a educação em saúde na qual contribuem para a prevenção e promoção da saúde de modo geral. ${ }^{1}$

Considerando o conceito de Nietsche, tecnologia é o resultado de processos concretizados a partir de experiência cotidiana e da pesquisa, para o desenvolvimento de um conjunto de conhecimentos científicos para a construção de produtos materiais ou não, com a finalidade de provocar intervenções sobre uma determinada situação prática. Além disso, as tecnologias desenvolvidas por enfermeiros devem ter como finalidade facilitar seu trabalho e melhorar a qualidade da assistência por eles prestada. ${ }^{4}$

Inserida nessa perspectiva, a educação em saúde como processo orientado para a utilização de estratégias que ajudem o indivíduo a adotar condutas que permitam um estado saudável, continua a ser objeto de reflexão crescente por parte de políticos, instituições, grupos profissionais e mesmo autores isolados de artigos científicos ou literatura específica. ${ }^{5}$ Frente a isso, a estratégia utilizada com o auxílio de tecnologias educacionais pode ser bastante eficaz. Entretanto, antes de se lançarem produtos para serem utilizados como instrumentos didáticos, é preciso fazer um ensaio com eles a fim de se conhecer sua eficácia e sua eficiência.

O preparo para o autocuidado e a promoção da saúde vai além de meras informações sobre como "controlar" uma condição crônica de saúde. Por isso, no que se refere a responsabilidade para a criação de ações para o cuidado, a instauração de um processo de conhecimento faz-se necessário para o desenvolvimento de um trabalho educativo com as pessoas envolvidas na busca da qualidade de vida. ${ }^{6}$

A mulher submetida à mastectomia pode vir a apresentar uma série de dificuldades ao reassumir sua vida profissional, social, familiar e sexual. Esta fase torna-se, muitas vezes, limitante e de difícil adaptação, fazendo-a depender de uma rede de suporte para o enfrentamento dessa nova condição, sentindo a necessidade de se manter informada a respeito dos cuidados indispensáveis depois da cirurgia para a seguir, se tornar agente ativa no seu processo de reabilitação. ${ }^{7}$

Dessa forma, acredita-se que a utilização de um manual educativo como estratégia e instrumento de apoio terapêutico fundamentado em termos científicos, contendo proposta de atividades selecionadas para recuperar, desenvolver ou reforçar as capacidades físicas, mentais e sociais, possa promover a saúde e a reinserção social das mulheres mastectomizadas e, ao mesmo tempo, melhorar a sua vida. Considera-se o instrumento um recurso essencial para o autoconhecimento dessas mulheres sobre o câncer de mama e poderá ser de extrema utilidade na sua recuperação e no retorno às atividades cotidianas. Portanto, esperase que, o manual educativo, após a sua validação, torne-se uma tecnologia educacional ao alcance dos pacientes e da enfermagem.

O conceito de validade é abordado como sendo o grau em que um instrumento mostra-se apropriado para mensurar o que supostamente ele deveria medir. Assim, quando se submete um instrumento ao procedimento de validação, na realidade não é o instrumento em si que está sendo validado, mas sim o propósito pelo qual o instrumento está sendo usado. ${ }^{8}$ 
Contudo, a determinação da validade é facilitada quando múltiplas medidas são empregadas para responder a uma dada questão da pesquisa. A convergência de resultados, obtidos quando é usada variadas técnicas, possibilita aumento da confiabilidade e validade dos achados do estudo e sua utilização na prática. Por isso, há várias maneiras de se verificar a validade de um instrumento. No entanto, neste estudo, optou-se por trabalhar a validação de conteúdo e de aparência. . $^{9-11}$

A validade de conteúdo é um método baseado, necessariamente, no julgamento. Para esta tarefa é chamado um grupo de juízes ou peritos com experiência na área do conteúdo, ao qual caberá analisar os itens e julgar se eles são abrangente e representativo, ou, ainda, se o conteúdo de cada item se relaciona com aquilo que se deseja medir. O pesquisador deve determinar, a priori, o número de validadores e a porcentagem de concordância esperada para se poder decidir sobre o destino de cada item. É também necessário instruir os avaliadores sobre como devem proceder à validação, fornecendo-lhes um formulário próprio para registro de seus julgamentos. ${ }^{10}$

Já a validade de aparência ou de face, também considerada uma forma subjetiva de validar o instrumento, consiste no julgamento de um grupo de juízes quanto à clareza dos itens, facilidade de leitura, compreensão e forma de apresentação do instrumento. ${ }^{9}$ Trata-se de uma avaliação superficial realizada por aqueles que se utilizarão do instrumento. Por conseguinte, não deve ser usada como um critério isolado, pois neste tipo de validade não são conferidas propriedades de medida. ${ }^{11}$

Frente ao que foi exposto, tem-se o propósito de validar um manual educativo para contribuir no autocuidado da mulher na reabilitação da mastectomia quanto à validade de conteúdo e de aparência.

\section{TRAJETÓRIA METODOLÓGICA}

Trata-se de uma pesquisa de desenvolvimento metodológico. Esta tem seu foco no desenvolvimento, avaliação e aperfeiçoamento de instrumentos e de estratégias metodológicas. ${ }^{8}$ Dessa maneira, a presente proposta tenciona a validação de um manual educativo, contendo assuntos de interesse das mulheres com câncer de mama, como material e método para se tornar uma tecnologia educativa e estratégia a ser usada na prática assistencial de enfermeiros.
A proposta metodológica para a validação do instrumento foi adaptada dos critérios estabelecidos no modelo de Pasquali, ${ }^{11}$ que envolve a teoria da elaboração de instrumentos de medida de fenômenos subjetivos e é composta por três conjuntos de procedimentos: teóricos, empíricos (experimentais) e analíticos (estatísticos). O primeiro procedimento contempla a fundamentação teórica sobre o construto para o qual se quer elaborar um instrumento de medida; o segundo consiste nas etapas e técnicas de aplicação do instrumento piloto, bem como na coleta de informações que possam avaliar as propriedades psicométricas do instrumento; e o terceiro, os procedimentos analíticos, determina as análises estatísticas dos dados com vistas à validação do instrumento.

Em virtude de o instrumento a ser validado se constituir de um manual educativo e não de uma escala psicométrica, procedeu-se a adaptações da teoria ora apresentada usando apenas os procedimentos teóricos.

Para a escolha dos participantes do estudo, utilizou-se da amostragem não probabilística intencional cuja principal característica é não fazer uso de formas aleatórias de seleção. Nesta, o pesquisador está interessado na opinião (ação, intenção, etc.) de determinados elementos da população, mas não em sua representatividade numérica. ${ }^{12}$ Portanto, para a validação do construto foram selecionados 14 profissionais para comporem os juízes especialistas e, para a análise semântica, 9 mulheres mastectomizadas.

A análise dos juízes, também chamada de análise de construto procurou verificar a adequação da representação comportamental dos itens. Para participar desta análise, os juízes devem ser peritos na área da tecnologia construída, pois sua tarefa consiste em ajuizar se os itens avaliados estão se referindo ou não ao propósito do instrumento em questão. Uma concordância de pelo menos $80 \%$ entre os juízes poderá servir de critério de decisão sobre a pertinência e/ou aceitação do item que teoricamente se refere.

Compuseram o comitê de juízes, 14 profissionais. Dentre eles: três médicos, cinco enfermeiros, três fisioterapeutas, um terapeuta ocupacional, um pedagogo e um comunicador social com o objetivo de refinar a relação das temáticas e avaliar sua pertinência conceitual referente à reabilitação das mulheres mastectomizadas. Quanto ao número ímpar de profissionais por categoria, foi induzido, pois alguns estudos têm mostrado a importância desta condição para evitar questionamentos dúbios. ${ }^{13}$ 
Como parâmetros de análise para a seleção dos especialistas, foram estabelecidos: a titulação, a produção científica e o tempo de atuação com a temática em discussão. Fizeram parte deste comitê apenas os juízes cujo perfil preenchia pelo menos três ou mais critérios, exceto o profissional de pedagogia e de comunicação social, tendo em vista que eles avaliaram o manual de acordo com a didática e com a aparência.

Os juízes-especialistas foram convidados a participar mediante contato formal através de carta-convite e ao aceitar, o participante preenchia o Termo de Consentimento Livre e Esclarecido e recebia uma cópia do manual para ser avaliado juntamente com seu respectivo instrumento de avaliação, dentro de um prazo de vinte dias.

Por último, o manual foi submetido à análise semântica e examinado quanto à inteligibilidade. Para essa etapa, foram escolhidas 9 mulheres conforme critérios de inclusão e divididas em três grupos denominados de 1, 2 e 3, organizados de acordo com o nível de instrução de cada uma.

Essa etapa justifica a ressalva de que antes de partir para uma validação final do instrumento piloto, este deve ser submetido a uma análise teórica dos itens por meio da análise semântica (populaçãoalvo). Esta tem como objetivo precípuo verificar se todos os itens são compreensíveis para os membros da população à qual o instrumento se destina. ${ }^{11}$

Para essa etapa, utilizou-se da técnica de brainstorming, a qual se constitui de grupos de até quatro pessoas, começando com sujeitos do estrato mais baixo da população-alvo (Grupo 1), e em seguida com um grupo do estrato mais alto (Grupo 2). Se o item for compreendido pelo Grupo 1, passase para o outro grupo. Em caso negativo, é preciso rever considerações do grupo. Quanto ao Grupo 2, deverá ser realizada uma sessão de verificação no intuito de evitar que os itens se apresentem demasiadamente simples para tais pessoas. ${ }^{11}$

O Grupo 1 foi composto por mulheres com baixo nível de escolaridade (ensino fundamental); o Grupo 2, por mulheres com nível médio (ensino médio); e o Grupo 3 por mulheres com nível superior (universitário).

O processo de validação com as mulheres foi realizado individualmente, em seu próprio domicílio, por meio da leitura do manual e do preenchimento do instrumento auto-aplicado, ambos sem interferência da pesquisadora. Após a leitura e análise do manual, as mulheres devolveram o instrumento de avaliação preenchido no prazo estabelecido. Após a entrega do material pelos três estratos, o manual foi analisado novamente pela pesquisadora e orientadora, e tentou-se acatar as sugestões pertinentes.

A coleta de dados foi realizada no período de abril a junho de 2006 em dois momentos metodológicos. Primeiro, a avaliação dos 14 juízesespecialistas (profissionais); segundo, a análise semântica de nove mulheres mastectomizadas escolhidas conforme critérios preestabelecidos para ambos.

Os dados foram coletados por meio de questionários individuais na forma de escala Likert com itens distribuídos em três blocos de análise. Optou-se por dois tipos de questionários por terem sido dois tipos de avaliações. Enquanto o primeiro questionário elaborado, ${ }^{13}$ traz uma formatação mais complexa, requerendo mais conhecimentos sobre a temática do câncer de mama e do processo de validação, o segundo apresenta questões para avaliação da dificuldade e da conveniência de materiais educativos, denominado de Suitability Assessment of Materials (SAM). ${ }^{14}$

Os dados captados dos instrumentos receberam tratamento descritivo e foram tabulados, interpretados, processados e analisados, utilizando-se os programas computacionais Excel 2000 e o Software SPSS versão 10.0 for windows, a fim de se obter resultados que permearam a etapa final do estudo.

Na organização dos dados, usaram-se tabelas. Os escores foram descritos por medidas estatísticas: média, desvio padrão, mínimo, mediana e máximo das variáveis estudadas. Foi também calculada a adequação da representação comportamental dos itens.

Com vistas a essa análise, reagrupou-se as opções de respostas de 1, 2, 3 e 4 com 1 e $2(+1), 3$ (0) e $4(-1)$, onde a resposta de cada juiz poderia variar de -1 a +1 e quanto mais próxima de +1 , maior a concordância entre eles de que o item era pertinente (índice de concordância). A partir das respostas dos juízes foi possível calcular as médias de concordância que variaram, como esperado, entre -1 e +1 . Seguindo a análise de cada item, em relação a essas médias obtidas, a maioria dos itens ficou com médias positivas e para as que obtiveram médias inferiores ao esperado, o item foi ajustado e o conteúdo acatado.

Convém ressaltar, que a maioria das sugestões propostas pelos avaliadores do instrumento foram repetidas, mas acatadas em sua integralidade, não havendo necessidade de reavaliação por todos os membros, sendo somente enviado para os avaliadores que tiveram suas sugestões questionadas. 
Conforme os preceitos ético-legais, a pesquisa atendeu as normas da resolução N¹96/96, além da aprovação do Comitê de Ética em Pesquisa do Hospital do Câncer do Ceará, no qual obteve a anuência com o protocolo de $\mathrm{N}^{\circ}$ 02/2006.

\section{RESULTADOS E DISCUSSÃO}

De posse dos instrumentos preenchidos e do manual com as devidas sugestões, iniciou-se a organização das informações. Como se tratava de várias informações, decidiu-se separar as informações captadas nos questionários das sugestões feitas no próprio manual, pois quando compiladas formaram um conjunto de informações importantes que não poderiam ser desprezadas.

A princípio, os participantes foram divididos em dois grupos. O Grupo 1, formado pelos juízesespecialistas, e o Grupo 2, pelas mulheres mastectomizadas. Em ambos os grupos, foram realizados tratamentos numéricos, apresentando as variáveis encontradas em cada instrumento de acordo com a freqüência e expostos na forma de gráficos e tabelas.

Durante a leitura, os especialistas foram orientados a anotar no próprio manual as correções e recomendações que julgassem necessárias. Dessa orientação, surgiram as sugestões consideradas pertinentes, as quais foram acatadas para o aperfeiçoamento do manual educativo proposto.

Conforme foi encontrado, a maioria dos problemas identificados foram: alterações de determinados termos ou expressões, por meio da substituição, exclusão ou acréscimo de palavras que facilitariam a compreensão da populaçãoalvo-mulheres mastectomizadas.

Entre os problemas detectados, "atualização da literatura", "informações erradas sobre a ação do hormônio tamoxifeno", "acrescentar informações em quimioterapia", considera-se que eles tenham sido identificados por já existirem assuntos atuais e de relevância para as mulheres que não foram citados, talvez pelo tempo decorrido desde sua elaboração até o momento atual.

A sugestão "substituição de termos" foi encontrada em quase todos os tópicos. Os termos técnicos e os eufemismos desnecessários devem ser evitados. A linguagem deve ser clara, simples e direta, devendo ser evitado a ordem inversa das orações, frases complexas ou longas demais, assim como qualquer informação não relevante. Em benefício da clareza e objetividade é necessário utilizar um vocabulário adequado à clientela. ${ }^{15}$ Dessa forma, o conteúdo deve transmitir clara- mente a informação e/ou orientação para que o público-alvo o entenda e não haja possibilidade de interpretações errôneas.

No processo de validação de conteúdo, as respostas dos juízes foram analisadas de forma quantitativa, por meio dos itens do instrumento de coleta que abordavam blocos de análise com as opções de resposta. Para emitir sua opinião, os especialistas responderam às questões entre quatro níveis. Estes variaram de: Totalmente Adequado (TA); Adequado (A); Parcialmente Adequado (PA); Inadequado (I).

A seguir, na Tabela 1, apresentam-se as respostas obtidas com a coleta de dados e o índice de concordância de cada item avaliado. Essa apresentação obedece à ordem do instrumento de avaliação conforme a seqüência dos blocos de itens com as questões a serem avaliadas.

Tabela 1 - Respostas obtidas dos juízes-especialistas segundo os objetivos, estrutura e apresentação e relevância do instrumento. Fortaleza - CE, 2006.

\begin{tabular}{lcccc}
\hline & \multicolumn{5}{c}{ Escores (N= 14) } \\
\cline { 2 - 5 } Itens & TA & A & PA & I \\
\hline Objetivos & & & & \\
1.1 & 8 & 5 & 1 & 0 \\
1.2 & 6 & 7 & 1 & 0 \\
1.3 & 5 & 7 & 2 & 0 \\
1.4 & 7 & 4 & 3 & 0 \\
1.5 & 5 & 8 & 1 & 0 \\
Estrutura e apresentação & & & \\
2.1 & 6 & 7 & 1 & 0 \\
2.2 & 5 & 4 & 5 & 0 \\
2.3 & 7 & 5 & 2 & 0 \\
2.4 & 5 & 4 & 4 & 1 \\
2.5 & 5 & 6 & 3 & 0 \\
2.6 & 3 & 6 & 4 & 1 \\
2.7 & 4 & 7 & 3 & 0 \\
2.8 & 7 & 5 & 2 & 0 \\
2.9 & 9 & 4 & 1 & 0 \\
2.10 & 8 & 4 & 2 & 0 \\
2.11 & 8 & 6 & 0 & 0 \\
2.12 & 8 & 3 & 1 & 2 \\
Relevância & & & & \\
3.1 & 8 & 5 & 1 & 0 \\
3.2 & 6 & 7 & 1 & 0 \\
3.3 & 5 & 7 & 2 & 0 \\
3.4 & 9 & 4 & 1 & 0 \\
3.5 & 8 & 5 & 0 & 1 \\
\hline Total & $\mathbf{1 4 2}$ & $\mathbf{1 2 0}$ & $\mathbf{4 1}$ & $\mathbf{5}$ \\
\hline & & & \\
& & & &
\end{tabular}

Escores: TA= Totalmente Adequado, $\mathrm{A}=$ Adequado, $\mathrm{PA}=$ Parcialmente Adequado, I= Inadequado. 
As respostas ora apresentadas, referem-se aos três blocos de itens - 1) objetivos; 2) estrutura e apresentação; e 3) relevância - sobre o manual avaliado pelos juízes-especialistas, de forma que se os quatorze juízes respondessem todos os itens, o primeiro bloco receberia setenta respostas, o segundo 168 e o terceiro setenta.

Como mostra a Tabela 1, houve uma tendência dos juízes a optarem pelas respostas de forma concordante. Ao analisar todos os itens, a maioria das respostas ficou entre TA (142) e A (120). Diante disso, pode-se inferir que não houve indicação significativa de discordância, pois dos 22 itens e das quatro opções de respostas, apenas cinco obtiveram escore I.

Bloco 1: esse bloco (objetivos) refere-se aos propósitos, metas ou fins a serem atingidos com a utilização do manual. Nele, as respostas foram as seguintes: 31 para TA, 31 para A e 8 para PA. Portanto, conforme se infere, das 70 (100\%) opções de respostas, $62(88,5 \%)$ foram para TA e A. Sobre este aspecto, o manual é adequado quanto aos objetivos propostos.

Um material bem elaborado ou uma informação de fácil entendimento, melhora o conhecimento e a satisfação do paciente, desenvolve ações que influenciam o padrão de saúde e favorece a tomada de decisão, além de contribuir na redução do uso dos serviços e dos custos com a saúde. ${ }^{16}$

Conforme foi sugerido por um dos juízes, acrescentamos informações atuais sobre novas técnicas de cirurgias conservadoras. Esta sugestão é procedente, pois essas técnicas estão sendo adotadas pelas recentes linhas de pesquisa que procuram definir o papel da preservação dos linfonodos axilares, com base na biópsia do linfonodo sentinela e, da limitação da ressecção mamária. Ao considerar essa sugestão, tentou-se introduzir conhecimentos atuais e necessários para o entendimento da mulher de forma que estivessem no nível de compreensão delas.

Bloco 2: esse bloco (estrutura e apresentação) refere-se à forma de apresentar as orientações. Isto inclui sua organização geral, sua estrutura, estratégia de apresentação, coerência e formatação. As respostas foram: 75 para TA, 61 para A, 28 para PA e 4 para I. Portanto, das 168 (100\%) opções de respostas, $136(80,95 \%)$ foram para TA e A, o que torna o manual válido quanto a esse bloco.

É comum encontrar-se impressos com ilustrações fora do contexto sociocultural, impressão pouco legível, textos com linguagem bastante técnica, períodos e palavras longas. Tais características podem diminuir o interesse pela leitura e/ou dificultar a compreensão. Desse modo, o material torna-se inadequado à maioria da clientela, e além de comprometer a compreensão, poderá também interferir no processo educativo. ${ }^{17}$

Para esse bloco também foram detectados erros ortográficos. Diante disso, sugeriu-se uma revisão de texto. Sobre essa sugestão é necessário relatar a importância da língua portuguesa para a área médica e/ou saúde. Visto serem os profissionais de saúde responsáveis por assistir o paciente, orientar, realizar procedimentos e técnicas, estes devem ser congruentes e expressarem devidamente o português, seja de forma falada ou escrita. Assim, o manual foi revisado pela pesquisadora e pela orientadora para, posteriormente, ser submetido a uma revisão gramatical mais apurada por profissional especializado. ${ }^{18}$

Bloco 3: esse bloco (relevância) refere-se as características que avaliam o grau de significação do material educativo. As respostas foram as seguintes: 36 para TA, 28 para A, 5 para PA e 1 para I. Desse modo, das 70 (100\%) opções de respostas, 64 $(91,42 \%)$ foram para TA e A, o que torna o manual válido para esse bloco também.

Como é notório, o processo de aquisição e aprofundamento de conhecimentos, de domínio de habilidades e de tomada de decisão é facilitado, entre outros recursos, pela utilização de material impresso. Para os pacientes em processo de reabilitação, a educação é decisiva por apoiar e facilitar a tomada de decisões, e as informações escritas ou orais devem-lhes ser dirigidas com o objetivo de ajudá-los a determinarem as metas do autocuidado e a buscarem soluções para os problemas enfrentados. Esse recurso é de grande relevância tendo em vista que um número considerável de pacientes encontra dificuldades para adquirir informações básicas e vitais necessárias à saúde, as quais, predominantemente, são apresentadas na forma impressa.

A análise da representação comportamental dos itens é o nome dado para o valor da estatística calculada que corresponde à média aritmética dos escores do item analisado pelos avaliadores (1 é usado quando a avaliação é positiva, 0 quando não é nem positiva nem negativa e -1 quando a avaliação é negativa).

Para executar esses cálculos procedeu-se a uma re-categorização dos escores, considerando: concordância, quando o item é avaliado como TA 
ou $\mathrm{A}=$ escore 1 ; indecisão, quando o item é avaliado como é PA = escore 0 ; discordância, quando o item é avaliado como I = escore $\mathbf{- 1}$.

Foram considerados validados os itens que obtiveram nas respostas índices de concordância entre os juízes maior ou igual a $80 \%$. Apesar da literatura apontar um índice de concordância maior ou igual a $70 \%$, optou-se por um índice de maior concordância por não ter conhecimento de estudos já realizados validando manuais para mulheres mastectomizadas.

A Tabela 2 apresenta os índices percentuais de concordância entre os juízes no enunciado de cada bloco e de cada item. Nela se destacam os índices inferiores a 0,8 (80\%).

Tabela 2 - Índices percentuais de concordância entre os juízes, segundo a avaliação de conteúdo do instrumento. Fortaleza - CE, 2006.

\begin{tabular}{|c|c|}
\hline Itens & Índice percentual \\
\hline $\begin{array}{l}\text { Objetivos } \\
1.1\end{array}$ & 0,93 \\
\hline 1.2 & 0,93 \\
\hline 1.3 & 0,86 \\
\hline 1.4 & $0,79^{a}$ \\
\hline 1.5 & 0,93 \\
\hline $\begin{array}{l}\text { Estrutura e apresentação } \\
2.1\end{array}$ & 0,93 \\
\hline 2.2 & $0,64^{b}$ \\
\hline 2.3 & 0,86 \\
\hline 2.4 & $0,57^{b}$ \\
\hline 2.5 & $0,79^{a}$ \\
\hline 2.6 & $0,57^{b}$ \\
\hline 2.7 & $0,79^{a}$ \\
\hline 2.8 & $0,79^{a}$ \\
\hline 2.9 & 0,93 \\
\hline 2.10 & 0,86 \\
\hline 2.11 & 1,00 \\
\hline 2.12 & $0,64^{b}$ \\
\hline $\begin{array}{l}\text { Relevância } \\
3.1\end{array}$ & 0,93 \\
\hline 3.2 & 0,93 \\
\hline 3.3 & 0,86 \\
\hline 3.4 & 0,93 \\
\hline 3.5 & 0,86 \\
\hline
\end{tabular}

Obs.: ${ }^{\mathrm{a}}$ corresponde ao índice limítrofe de concordância; ${ }^{\mathrm{b}}$ corresponde ao índice abaixo do parâmetro definido de concordância.
Nessa etapa de validação, alguns itens do instrumento e suas respectivas definições operacionais atingiram a meta proposta de $80 \%$ de concordância entre os juízes. Os itens 1.4, 2.5, 2.7 e 2.8 tiveram avaliação 0,79 . De acordo com tais avaliações, os juízes não consideraram estes itens adequados. Foi, então, necessário fazer algumas modificações na representação desses itens para o manual. Porém, como este valor está bastante próximo de 0,8 , as modificações sugeridas são mínimas, mas pelo critério adotado, foram feitas.

Já os itens 2.2, 2.4, 2.6 e 2.12 tiveram índices abaixo do parâmetro adotado e, conseqüentemente, precisaram ser reformulados na representação que eles têm para o manual. Assim, procederamse às reformulações conforme as sugestões acatadas e apresentadas anteriormente por achá-las pertinentes. Convém ressaltar que alguns itens, apesar de terem atingido o índice proposto $(0,8)$, também foram reformulados por também considerarmos as sugestões dos juízes significantes para a melhoria do instrumento.

Na Tabela 3, apresenta-se a distribuição das respostas obtidas da análise semântica, segundo as mulheres mastectomizadas.

As respostas apresentadas nesta tabela referem-se aos cinco blocos de itens (objetivos, organização, estilo da escrita, aparência, motivação) sobre o manual avaliado pelas mulheres mastectomizadas, de forma que o primeiro bloco receberia 27 respostas, o segundo 63, o terceiro 54 , o quarto 36 e o quinto 54 , se as nove mulheres respondessem a todos os itens.

Ao se analisar todos os itens do instrumento, a maioria das respostas ficou entre TA (114) e A (114). Diante disso, pode-se inferir que nesse grupo também não houve indicação significativa de discordância, pois dos 26 itens e quatro opções de respostas, apenas um item obteve escore I.

Embora as mulheres tenham considerado o manual como um instrumento adequado para seu manuseio, o baixo índice de escolaridade favoreceu a ocorrência de limitado número de considerações sobre o instrumento avaliado. Conforme observado, as sugestões feitas surgiram das mulheres com nível de escolaridade superior. 
Tabela 3 - Freqüências de respostas obtidas das mulheres mastectomizadas segundo os objetivos, organização, estilo da escrita, aparência e motivação do instrumento. Fortaleza - CE, 2006.

\begin{tabular}{|c|c|c|c|c|}
\hline \multirow[b]{2}{*}{ Itens } & \multicolumn{4}{|c|}{ Escores $(\mathrm{N}=9)$} \\
\hline & TA & A & PA & I \\
\hline $\begin{array}{l}\text { Objetivos } \\
1.1\end{array}$ & 5 & 4 & 0 & 0 \\
\hline 1.2 & 5 & 4 & 0 & 0 \\
\hline 1.3 & 4 & 4 & 0 & 0 \\
\hline $\begin{array}{l}\text { Organização } \\
2.1\end{array}$ & 6 & 3 & 0 & 0 \\
\hline 2.2 & 2 & 7 & 0 & 0 \\
\hline 2.3 & 4 & 4 & 1 & 0 \\
\hline 2.4 & 6 & 3 & 0 & 0 \\
\hline 2.5 & 5 & 4 & 0 & 0 \\
\hline 2.6 & 6 & 2 & 1 & 0 \\
\hline 2.7 & 5 & 4 & 0 & 0 \\
\hline $\begin{array}{l}\text { Estilo da escrita } \\
3.1\end{array}$ & 3 & 6 & 0 & 0 \\
\hline 3.2 & 4 & 5 & 0 & 0 \\
\hline 3.3 & 4 & 4 & 1 & 0 \\
\hline 3.4 & 3 & 6 & 0 & 0 \\
\hline 3.5 & 5 & 3 & 1 & 0 \\
\hline 3.6 & 6 & 3 & 0 & 0 \\
\hline $\begin{array}{l}\text { Aparência } \\
4.1\end{array}$ & 6 & 3 & 0 & 0 \\
\hline 4.2 & 5 & 3 & 1 & 0 \\
\hline 4.3 & 3 & 5 & 1 & 0 \\
\hline 4.4 & 3 & 5 & 1 & 0 \\
\hline $\begin{array}{l}\text { Motivação } \\
5.1\end{array}$ & 5 & 4 & 0 & 0 \\
\hline 5.2 & 5 & 4 & 0 & 0 \\
\hline 5.3 & 1 & 8 & 0 & 0 \\
\hline 5.4 & 4 & 5 & 0 & 0 \\
\hline 5.5 & 4 & 5 & 0 & 0 \\
\hline 5.6 & 5 & 3 & 1 & 0 \\
\hline Total & 114 & 114 & 8 & 1 \\
\hline
\end{tabular}

Escores: TA= Totalmente Adequado, A= Adequado, PA= Parcialmente Adequado, I= Inadequado.

\section{CONSIDERAÇÕES FINAIS}

A necessidade de criação de novos artifícios coloca a Enfermagem como uma ciência em construção. Ao aliar conhecimento científico aos procedimentos técnicos, a enfermeira utiliza-se das diversas tecnologias para promoção, manutenção e recuperação da saúde, exercendo com criatividade a arte do cuidar e por isso, deverá estimular nos profissionais o desejo, a motivação e a intencionalidade de inventar tecnologias voltadas a facilitar e tornar mais ágil o seu trabalho, com a produção do conhecimento extraída de questões da práxis.

Diante disso tem-se a expectativa de que a elaboração e a validação deste manual educativo, sobre orientações à mulheres mastectomizadas, possam incentivar a construção de outros materiais didáticos, especialmente na área da enfermagem, pois ela precisa ampliar o exercício contínuo da atitude crítica diante das próprias produções; observar além do que lhe apresenta, como mais uma forma de obter maior visibilidade sobre o que a cerca; registrar e divulgar a produção do seu conhecimento e estar pronta a enfrentar os desafios impostos pelas ciências na profissão.

Para a mulher com diagnóstico de câncer de mama, a boa qualidade de vida não é sinônimo de uma reabilitação adequada. Contudo, os estudos sobre o uso de materiais educativos, a exemplo do manual, no processo de reabilitação de mastectomizadas, ainda são incipientes em nosso meio e esta investigação pode ser entendida como um ponto de partida para outras de natureza semelhante.

Nesse sentido, torna-se relevante a contribuição de tecnologias educativas escritas no contexto da educação em saúde e o papel desse recurso para se promover saúde, prevenir complicações, desenvolver habilidades e favorecer a autonomia e confiança do paciente. Como um componente da equipe interdisciplinar que desempenha a função de educador, o enfermeiro deve participar do processo de criação, desenvolvimento e avaliação do material educativo.

Acredita-se ter contribuído para fortalecer a prática educativa da enfermagem e, assim, melhorar a qualidade de vida da mulher mastectomizada, mesmo tendo a consciência de que, como se trata de manual educativo, este é um instrumento inacabado, portanto, deverá passar periodicamente por revisões apuradas para torná-lo sempre atualizado e útil na prática.

\section{REFERÊNCIAS}

1 Oliveira MS. Autocuidado da mulher na reabilitação da mastectomia: estudo de validação de aparência e conteúdo de uma tecnologia educativa [dissertação]. Fortaleza (CE): UFC/Programa de Pós-Graduação em Enfermagem; 2006.

2 Mancia JR, Leal SMC, Machado CS. Tecnologias e inventos de enfermeiras: cuidando com criatividade. Rev. Téc.-Cient. Enferm. 2003 Jan-Fev; 1 (1):18-21. 
3 Mendes IAC, Leite JL, Trevizan MA, Trezza MCSF, Santos RM. A produção tecnológica e a interface com a enfermagem. Rev. Bras. Enferm. 2002 Set-Out; 55 (5): 556-61

4 NietscheEA. Tecnologia emancipatória: possibilidade ou impossibilidade para a práxis de enfermagem? Rio Grande do Sul (RS): Unijuí, 2000.

5 Branco IMBHP. Prevenção do câncer e educação em saúde: opiniões e perspectivas de enfermagem. Texto Contexto Enferm. 2002 Maio-Ago; 14 (2): 242-8.

6 Francioni FF, Coelho MS. A superação do déficit de conhecimento no convívio com uma condição crônica de saúde: a percepção da necessidade da ação educativa. Texto Contexto Enferm. 2004 JanMar; 13 (1): 156-62.

7 Oliveira MS, Fernandes AFC, Melo EM, Barbosa ICFJ. Cuidados preoperatórios de mastectomía bajo la optica de la mujer. Rev. Cubana Enferm. 2005 Mayo-Ago; 21 (2): [on line] [acesso em 2006 Dez 5]. Disponível em: http://scielo.sld.cu/scielo.php?script=sci_issuetoc\& pid $=0864031920050002 \& \operatorname{lng}=$ pt\&nrm $=$ iso

8 Polit DF, Beck CT, Hungler BP. Análise quantitativa. In: Polit DF, Beck CT, Hungler BP. Fundamentos de pesquisa em enfermagem: métodos, avaliação e utilização. 5a ed. Porto Alegre (RS): Artmed; 2004. p.167-98.

9 Williamson MY. Research methodology and its application to nursing. New York (NY/USA): John Wiley \& Sons; 1981.

10 Cassiani SHB. A coleta de dados nas pesquisas em enfermagem: estratégia, validade e confiabilidade [dissertação]. Ribeirão Preto (SP): USP/EERP/

Programa de Pós-Graduação em Enfermagem; 1987.

11 Pasquali L. Psicometria: teoria e aplicações. Brasília (DF): UnB; 1997.

12 Marconi MA, Lakatos EM. Técnicas de pesquisa: planejamento e execução de pesquisas, amostragens e técnicas de pesquisas, elaboração, análise einterpretação de dados. 5a ed. São Paulo (SP): Atlas; 2002.

13 López ML. Uso de simulação filmada para avaliar o relacionamento interpessoal enfermeiro-paciente no cuidado ao adulto hospitalizado [doutorado]. Ribeirão Preto (SP): USP/Universidade de São Paulo. Escola de Enfermagem de Ribeirão Preto; 2004.

14 Doak CC, Doak GL, Root JH. Teaching patients with low literacy skill. 2nd ed. Philadelphia (PA/USA): Lippincott; 1996.

15 Silva GRF. Estimulação visual: prática educativa com mães na enfermaria mãe-canguru [dissertação]. Fortaleza (CE): UFC/Programa de Pós-Graduação em Enfermagem; 2005.

16 Serxner S. How readability of material affects outcomes. J.Vasc.Nurs. 2000; 18 (3): 97-101.

17 Moreira MF, Silva MIT. Readability of the educational material written for diabetic patients. On-line Braz. J. Nurs. 2005 Aug; 4 (2): [on-line] [acesso em 2006 Jan 15]. Disponível em: www.uff.br/nepae/ objn402moreiraetal.htm

18 Bacelar S, Galvão CC, Alves E, Tubino P. Expressões médicas errôneas: erros e acertos. Acta Cir. Bras. 2004 Set-Out; 19 (5): 582-4. 